\title{
COMMENT
}

\section{First aid for Medicaid: losses in children's health insurance}

\author{
Shetal Shah ${ }^{1}$, Alice A. Kuo ${ }^{2,3}$ and Heather L. Brumberg ${ }^{1}$ \\ Pediatric Research (2021) 89:8-11; https://doi.org/10.1038/s41390-020-01219-2
}

Children's health is the result of multiple social, behavioral, genetic, environmental and community factors. Utmost in importance in the US is enrollment in quality health insurance and access to care. In the US, public health insurance for children is provided mainly through Medicaid-a federal-state partnership that aims to insure children at lower levels of the income spectrum. Coverage is also provided by the Children's Health Insurance Program (CHIP), a federal grant program that provides funds to insure children with parental incomes above the Medicaid threshold, but still at a level in which private insurance is financially burdensome. Public health insurance enrollment via Medicaid and CHIP, particularly for young children under the age of 6 years, is associated with improved preventive care, immunization rates and reduced emergency room visits and hospitalizations. $^{1-5}$ From 2008 to 2016, the rate of uninsured children dropped annually. However since 2016, rates of uninsured children are rebounding. The purpose of this commentary is to review policy factors that contributed to this change in insurance coverage.

This dramatic change is the result of threats to the health insurance safety net in the form of reduced payments, and barriers to eligibility and enrollment that have been proposed or implemented. Experienced losses in pediatric health insurance coverage could have been worse. Recent data from 2016 to 2018 show that higher income eligibility thresholds and payment rates for Medicaid provided a partial buffer against losses in children's health insurance coverage.

Medicaid is the single largest insurer of children. ${ }^{6}$ The program, with CHIP, covers $44-45$ million $(48 \%)$ of all US children., ${ }^{1,7}$ Of all Medicaid enrollees, nearly half (48\%) are children. CHIP covers approximately eight million children, $89 \%$ of which live in families who are below $200 \%$ of the Federal Poverty Level. ${ }^{1}$ Significant racial/ethnic differences exist within public health insurance coverage-almost $55 \%$ of Black and Latinx children are covered by public insurance, in contrast to only $24 \%$ of Asian children. ${ }^{8}$

Adults who were insured by Medicaid in childhood prior to age 6 years had reduced rates of metabolic syndrome (i.e., hypertension, diabetes, heart disease and obesity).9,10 These studies demonstrate that providing public health insurance to eligible children is cost-effective and saves $\sim \$ 3000 /$ child/year. $^{1}$ Medicaid expansion, a provision of the Affordable Care Act (ACA), incentivized states to increase Medicaid income eligibility requirements to $\sim 138 \%$ of the federal poverty level, and federal renewals of CHIP have led to significant and consistent decreases in the rate of uninsured children from 2008 to $2016 .{ }^{9}$ However, beginning in 2016, the numbers of uninsured children again began increasing-a result of major federal policy changes enacted over the past 4 years (Fig. 1).

Adjustments to elements of eligibility, enrollment and access to care within public health insurance programs have direct impacts on national rates of child uninsurance. Over the last several years, changes to the delivery of Medicaid have led to a rebound in the rates of uninsured children, which have increased annually from 2016 to 2018 , from 4.7 to $5.5 \%$, reflecting a movement of 425,000 children off of public programs. ${ }^{11}$ These losses in children health insurance have been asymmetrically distributed. Overall, states that did not expand Medicaid have almost double the rates of uninsured children as states that accepted expansion. Further, from 2016 to 2018, the increase in uninsured children in nonexpansion states was $0.9 \%$, triple that of Medicaid expansion states-demonstrating again the vital public safety net role these programs offer children.

\section{PULLING OUT THE 'WELCOME MAT'}

Losses in the number of uninsured children are partially the result of changes in federal aspects of Medicaid funding and regulation. In 2017, a crucial aspect of increasing Medicaid participation, funding for the advertising, outreach, marketing and navigation of health insurance enrollment (termed, "Welcome Mat"), was reduced by $43 \%{ }^{12}$ The following year support was reduced to a total of $\$ 10$ million (an 84\% reduction from 2016). Outreach and enrollment funding is essential to educate families about eligibility for programs and to overcome barriers to Medicaid enrollment. Data from 2006 health reform efforts in Massachusetts showed among low-income families, a robust outreach and enrollment program was associated with a $16.3 \%$ increase in Medicaid enrollment and a $19.4 \%$ difference in participation compared to control states. ${ }^{13}$

Further, even when outreach funding is directed at adult Medicaid enrollment, more children benefit from Medicaid. From 2013 to 2015, rates of insured children increased 5.7\% if parents were Medicaid-eligible, compared with $2.7 \%$ if parents remained ineligible-a net increase of 710,000 low-income children. ${ }^{14}$ These data illustrate a major tenet of children's health insurance enrollment-programs that increase Medicaid coverage in adults have a pediatric effect. ${ }^{12,14,15}$

Adult-oriented programs do not just result in greater childhood Medicaid enrollment, but are linked with increased receipt of pediatric care. Nationally, parental Medicaid enrollment within the targeted income levels of the ACA Medicaid expansion is associated with a 45 -fold increased odds of children receiving

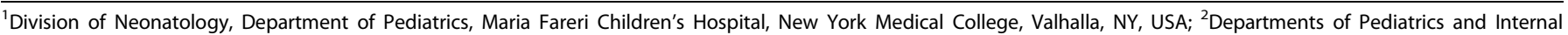

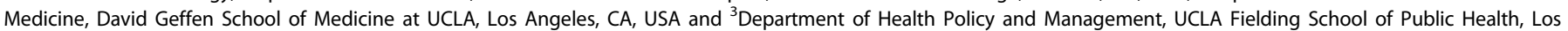
Angeles, CA, USA

Correspondence: Shetal Shah (shahs2@wcmc.com)

Received: 21 September 2020 Accepted: 25 September 2020

Published online: 20 November 2020 
well-child visits. ${ }^{15}$ Conversely, barriers to adult insurance enrollment may also cause spillover reductions in children's coverage. ${ }^{16}$

\section{MEDICAID WAIVERS AND REGULATORY BARRIERS}

To encourage innovation and state-based experimentation with healthcare insurance and delivery, the original Medicaid law allowed states to apply for a waiver of traditional coverage requirements. The premise was to allow states to test programs that would reduce costs or expand coverage.

Over the past 4 years, multiple states have sought and received federal approval for waivers to the Medicaid program that have curtailed parental public health insurance coverage. Six states have approved ( 2 implemented) work requirements for adults to remain Medicaid-eligible, resulting in reduced adult Medicaid coverage. ${ }^{17}$ In Arkansas, 18,000 beneficiaries lost Medicaid coverage; and Mississippi estimates a reduction of $8 \%$ in Medicaid enrollment based on this waiver. ${ }^{17,18}$ In states with very lowincome thresholds to lose Medicaid coverage, work requirements may squeeze out low-income workers. If a worker's wages, mandated via work requirements, exceed a state's income threshold for Medicaid eligibility, then parents may earn too much for public insurance but too little to afford health coverage from other sources.

Maintaining eligibility is critical to keeping rates of child insurance high. States with higher income limits for Medicaid

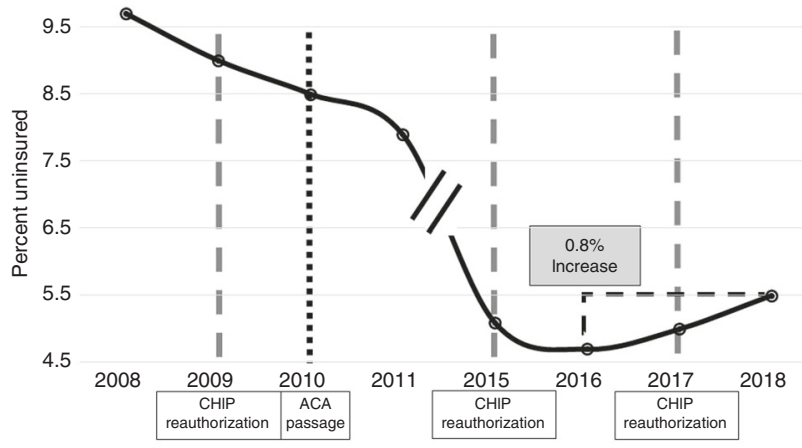

Fig. 1 Rate of child health uninsurance over time. After years of steady decline, the rate percentage of children without health insurance increased from 2016 to 2018. Changes in the percent of uninsured children are plotted with the years of Affordable Care Act (ACA) and Children's Health Insurance Program (CHIP) reauthorization. eligibility have significantly lower rates of child uninsurance and fared better than states with lower income eligibility from 2016 to 2018 (Fig. 2a, b). Several states have created eligibility and enrollment restrictions within the waiver program, including disenrolling Medicaid recipients for nonpayment of premiums, locking out recipients from re-enrollment for varying lengths of time and requiring documentation of Medicaid eligibility several times a year. Bureaucratic obstacles, such as Louisiana's regulation to verify Medicaid eligibility quarterly, or Tennessee's reliance on a lengthy paper renewal form, have resulted in significant losses in Medicaid coverage for parents. ${ }^{17}$

\section{MEDICAID PAYMENT REGULATIONS AND CHILDREN'S COVERAGE}

Eligibility and enrollment in public insurance are not synonymous with care. Obtaining health care for children is closely linked with Medicaid payments, particularly in regions where costs of practice are high. Within pediatrics, payment from Medicaid is roughly $60 \%$ of private insurance reimbursements. ${ }^{19}$ Increasing Medicaid payments to levels consistent with Medicare, a tenet of the ACA from 2010 to 2012, resulted in an increase in the number of children with Medicaid insurance potentially cared for by primary care pediatricians. ${ }^{20}$ Further, from 2016 to 2018, states with Medicaid payments above $75 \%$ of Medicare rates approached a lower percent-change in uninsured children (Fig. 3).

States have flexibility to adjust payments to ensure Medicaid recipients have access to care comparable to privately insured children. ${ }^{21}$ Yet the Centers for Medicare and Medicaid Services (CMS) indirectly exert influence over these payments via regulation. In early 2020, the federal government proposed a series of technical changes to the Medicaid Fiscal Accountability Rule, adjusting the calculation of Upper Payment Limits - funds used by states to incentivize providers to accept patients with Medicaid into care. The resulting decrease in physician payments for Medicaid patients raises significant concerns that access to care will be limited. ${ }^{20-22}$

The relationship between payments and access for publicly insured children is further jeopardized by actions from late January 2020 and the COVID-19 pandemic. In late January, CMS announced the Transformative Medicaid Healthy Adult Opportunity, an invitation to states to obtain Block Grants for state Medicaid programs. ${ }^{23}$ Under a Block Grant paradigm, states receive a fixed dollar amount for Medicaid, with no additional contributions for unexpected costs, which states must bear alone, without federal assistance. Currently, these costs would be shared
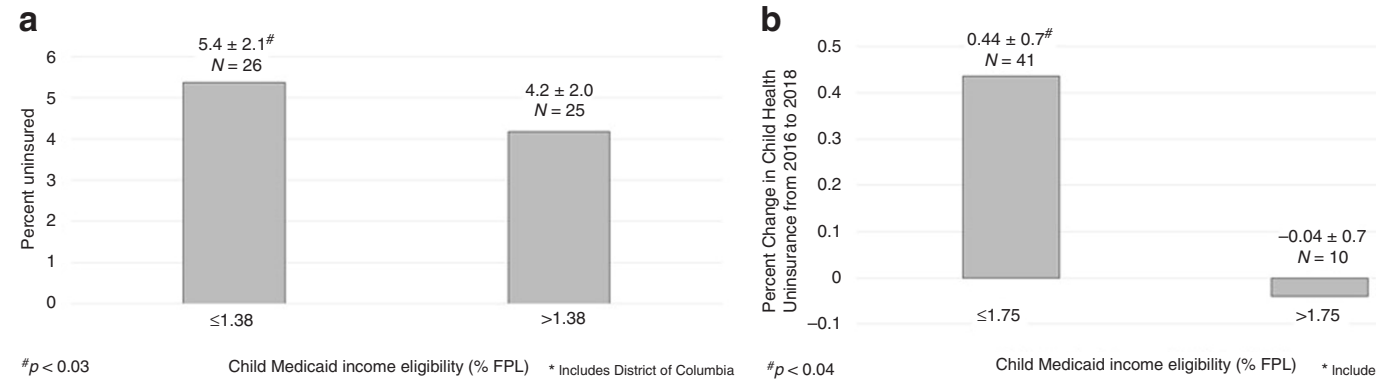

Child Medicaid income eligibility (\% FPL)

Fig. 2 Child Medicaid Income Eligibility and Markers of Child Uninsurance. a Child (6-18 years) Medicaid income eligibility (percentage of federal poverty level) vs. 2018 child uninsurance rate. States with child Medicaid Income Eligibility Limits $>138 \%$ of the Federal Poverty Level experienced a smaller increase in the percentage of uninsured children ( $p<0.03$, unpaired $t$ test). b Child (6-18 years) Medicaid income eligibility (percentage of federal poverty level) vs. percent change in child health uninsurance 2016-2018. States with child Medicaid Eligibility above $175 \%$ of the Federal Poverty Level experienced significantly lower percent change of uninsured children compared to states with lower eligibility levels $(p<0.04$, unpaired $t$ test). Data include 50 states and the District of Columbia from the "Children's Healthcare Report Card," from the Georgetown Center for Children and Families, available at: https://kidshealthcarereport.ccf.georgetown.edu/ and the Kaiser Family Foundation, Medicaid and CHIP, Trends in Income Eligibility for Children, available at: https://www.kff.org/medicaid/stateindicator/medicaid-income-eligibility-limits-for-children-ages-6-18/?currentTimeframe =0\&selectedDistributions =january-2020\&sortModel=\% 7B\%22colld\%22:\%22Location\%22,\%22sort\%22:\%22asc\%22\%7D. 

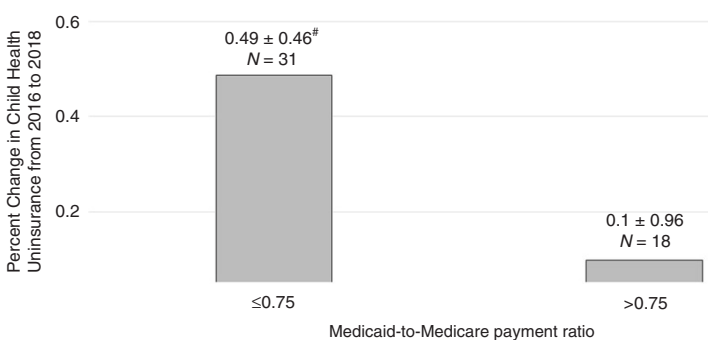

${ }^{\# p} p<0.06$

Medicaid-to-Medicare payment ratio

$>0.75$

Fig. 3 Medicaid-to-Medicare payment ratio vs. percent change in child health insurance 2016-18. States. Data from 49 states (excludes Tennessee) demonstrate states with a Medicaid-toMedicare payment ratio of $>0.75$ exhibited decreased changes in rates of uninsured children ( $p<0.06$, unpaired $t$ test). Data from the "Children's Healthcare Report Card," from the Georgetown Center for Children and Families, available at: https://kidshealthcarereport. ccf.georgetown.edu/ and the Kaiser Family Foundation, Medicaid and CHIP, Trends in Income Eligibility for Children, available at: https://www.kff.org/medicaid/state-indicator/medicaid-incomeeligibility-limits-for-children-ages-6-18/?currentTimeframe $=0$ \&selec tedDistributions=january-2020\&sortModel $=\% 7 \mathrm{~B} \% 22$ colld $\% 22: \% 22$ Location\%22,\%22sort\%22:\%22asc\%22\%7D.

with the federal government based on the state's Federal Medical Assistance Percentage Rate. Converting Medicaid financing to a fixed state payment alters the very nature of Medicaid, undermining its spirit as a robust federal-state partnership. Further, Block Grant formulas have consistently and overwhelmingly underestimated actual healthcare costs. Analysis of the theoretical impact of a 1981 Block Grant proposal found states would have cumulatively born an extra $\$ 76.6$ billion financial burden over 10 years, all but forcing states to curtail payment, eligibility, enrollment or access. ${ }^{24}$ Enactment of the 1995 Block Grant proposal would have shifted $\$ 18.5$ billion in costs to states. ${ }^{24}$

\section{COVID-19 AND MEDICAID}

Though conceived to accommodate unexpected costs like disease outbreaks, no existing public insurance program could foresee the widespread disruption the coronavirus pandemic would cause on rates of uninsured children. The national economic stress and the resultant job loss reduced the number of children covered by parental employer-sponsored insurance. ${ }^{25}$ At $20 \%$ unemployment, 25 million adults may lose coverage. ${ }^{26}$ However, when states are compared by Medicaid expansion status, differences exist in those who will be ultimately uninsured. ${ }^{26}$ Within expansion states, $53 \%$ of those losing employer-sponsored insurance would fall into the Medicaid safety net, compared to $33 \%$ in nonexpansion states.

Children should fare better, a result ascribed to CHIP in ensuring children with parents who earn above the Medicaid-threshold are insured. As a result of the COVID-19 pandemic, "only" $10 \%$ of children who lose coverage due to parental unemployment will remain uninsured. ${ }^{26}$ The pandemic will no doubt strain the safety net but also allow us to appreciate the vital support provided by robust public insurance programs. While many states were experiencing significant budgetary shortfalls pre-COVID, these strains will be exacerbated by the fiscal pressure placed on state and local governments, which are estimated to lose $\$ 600-\$ 765$ billion from sales and income tax loses. ${ }^{27}$ Further these estimates are yet to include the increased state costs of the pandemic associated with hospitals and first responders. ${ }^{28}$ As of this writing, the economic stimulus package passed by the House of Representatives in May (the Heroes Act) has not been acted on by the US Senate. The bill includes $\$ 1$ trillion dollars in state and county government relief, $\$ 915$ billion of which is flexible and not earmarked to any specific line item. ${ }^{29}$

If children are to thrive, they must be healthy, and there can be no health, without health insurance and access to providers. In the past few years, the rate of uninsured children has increased, reversing almost a decade of annual year-over-year improvements in children's health insurance coverage. Actions such as elimination of outreach/enrollment funding and implementation of Medicaid are associated with these reductions and create barriers to healthcare for both parents and children. These losses in coverage may also result in greater financial insecurity among low-income families. New proposals such as technical changes to the Medicaid Fiscal Accountability Rule, renewed calls for Block Grant proposals and the economic crisis associated with the COVID-19 pandemic further threaten children's healthcare coverage.

As health reform discussions are reinvigorated, the foundational role of public insurance must be considered and respected. The health insurance landscape is ever-changing and pediatricians and researchers must be made aware of quietly implemented regulatory changes that influence loss of children's health insurance coverage. This is especially true during the time of COVID-19, where disparities in access to care are widened and pediatricians burdened with increased clinical duties. Researchers need to continue to follow health outcomes associated with losses in insurance coverage to ensure Medicaid policy is evidencebased. Constant vigilance is required to help decipher these maneuvers and help understand the practical impact of these changes on clinical care. Ultimately, Medicaid may only be as strong as those who continue to advocate for it.

\section{AUTHOR CONTRIBUTIONS}

S.S. conceived the idea for the manuscript, authored the first draft and made critical revisions. A.A.K. made substantive additions to the manuscript and made critical revisions to the drafts. H.L.B. helped outline the draft of the manuscript and made critical revisions to the manuscript. All authors approved the final version prior to submission.

\section{ADDITIONAL INFORMATION}

Competing interests: The authors declare no competing interests.

Publisher's note Springer Nature remains neutral with regard to jurisdictional claims in published maps and institutional affiliations.

\section{REFERENCES}

1. Flores, G. et al. The health and healthcare impact of providing insurance coverage to uninsured children: a prospective observational study. BMC Public Health 17, 553 (2017).

2. Holl, J. L. et al. Evaluation of New York State's Child Health Plus: access, utilization, quality of health care and health status. Pediatrics 105, 711-718 (2000).

3. Szilagyi, P. G. et al. Improved access and qulity of care after enrollment in the New York State Children's Health Insurance Program (SCHIP). Pediatrics 113, e395-e404 (2004).

4. Kempe, A. et al. Changes in access, utilization and quality of care after enrollment into a state child health insurance plan. Pediatrics 115, 364-371 (2005).

5. Szilagyi, P. G. et al. Improved asthma care after enrollment in the State Children's Health Insurance Program in New York. Pediatrics 117, 486-496 (2006).

6. Shah, S. I. \& Brumberg, H. L. Predictions of the Affordable Care Act's impact on neonatal practice. J. Perinatol. 36, 586-592 (2016).

7. Javier, J. R., Hoffman, L. \& Shah, S. ACE closed: adverse childhood experiences, obesity, and long-term health. Pediatr. Res. 86, 420-422 (2019).

8. KIDS COUNT Data Center, Annie E. Casey Foundation. Children who have health insurance by health insurance type and by race and ethnicity in the United States. https://datacenter.kidscount.org/data/tables/9237-children-who-havehealth-insurance-by-health-insurance-type-and-by-race-and-ethnicity\#detailed/ 1/any/false/870/4038,4040,4039,2638,2597,4758,1353/5564/18293 (2016).

9. Wherry, L. R., Kenney, G. M. \& Sommers, B. D. The role of public health insurance in reducing child poverty. Acad. Pediatr. 16, S98-S104 (2016). 
10. Boudreaux, M. H., Golberstein, E. \& McAlpine, D. The long-term impacts of Medicaid exposure in early childhood: evidence from the program's origin. $J$. Health Econ. 45, 161-175 (2016).

11. Alker, J. Why are there more uninsured kids and what can we do about it? Georgetown Center for Children and Families https://ccf.georgetown.edu/2019/ 09/12/why-are-there-more-uninsured-kids-and-what-can-we-do-about-it/ (2019).

12. Jost, T. CMS cuts ACA advertising by 90 percent amid other cuts to enrollment outreach. Health Affairs Blog. https://www.healthaffairs.org/do/10.1377/ hblog20170901.061790/full/ (2017).

13. Sonier, J., Boudreaux, M. H. \& Blewett, L. A. Medicaid "welcome-mat" effect of Affordable Care Act implementation could be substantial. Health Aff. 32, 1319-1325 (2013).

14. Hudon, J. L. \& Moriya, A. S. Medicaid expansion for adults had measurable 'Welcome Mat' effects on their children. Health Aff. 36, 1643-1651 (2017).

15. Venkatarami, M., Pollack, C. E. \& Roberts, E. T. Spillover effects of adult Medicaid expansions on children's use of preventive services. Pediatrics 140, e20170953 (2017).

16. Szilagyi, P. G., Schuster, M. A. \& Cheng, T. L. The scientific evidence of child health insurance. Acad. Pediatr. 9, 4-6 (2009).

17. Henry J. Kaiser Family Foundation. Medicaid waiver tracker: approved and pending Section 1115 waivers by State. https://www.kff.org/medicaid/issue-brief/ medicaid-waiver-tracker-approved-and-pending-section-1115-waivers-by-state/ (2020).

18. Center on Budget and Policy Priorities. Taking away Medicaid for not meeting work requirements harms children. https://www.cbpp.org/sites/default/files/ atoms/files/4-4-18health.pdf (2020).

19. Muhuri, P. \& Machline, S. Differences in payments for child visits to office-based physicians: private versus Medicaid Insurance, 2010-2015. https://meps.ahrq. gov/data_files/publications/st504/stat504.pdf (2017).

20. Tang, S. S. et al. Increased Medicaid payment and participation by office-based primary care pediatricians. Pediatrics 141, e20172570 (2018).
21. Kaufman, M. J. Children's Hospital Association. Medicaid Program; Medicaid Fiscal Accountability Regulation; Federal Register, Vol. 84, No. 222, November 18 2019 [CMS-2393-P]. https://www.childrenshospitals.org/-/media/Files/CHA/Main/ Issues_and_Advocacy/Key_Issues/Medicaid/Letters and Testimony/2020/MFAR Comment_letter_Final_013120.pdf?la $=$ en\&hash $=416576$ F082614012A486DDAA AC448FD3E51D1D13 (2019).

22. Hudak, M. L., Helm, M. E. \& White, P. H. Principles of child health care financing. Pediatrics 140, e20172098 (2017).

23. Centers for Medicare and Medicaid Services. Trump administration announces transformative Medicaid Healthy Adult Opportunity 1/30/2020. Acad Pediatr. 1, 4-6. https://www.cms.gov/index.php/newsroom/press-releases/trump-adminis tration-announces-transformative-medicaid-healthy-adult-opportunity. (2020)

24. Lambrew, J. M. Making Medicaid a Block Grant Program: an analysis of the implications of past proposals. Milbank Quaterly 83, 41-63 (2005).

25. U.S. Department of Labor. COVID-19 Impact (U.S. Department of Labor, Washington, DC, 2020). https://www.dol.gov/ui/data.pdf.

26. Gangopadhyaya, A. \& Garrett, B. Unemployment, health insurance and COVID-19 recession. Urban Institute and Robert Wood Johnson Foundation. https://www. urban.org/sites/default/files/publication/101946/unemployment-healthinsurance-and-the-covid-19-recession_1.pdf (2020).

27. Center on Budget and Policy Priorities. How much would each state receive through the Coronavirus State Fiscal Relief Fund in the Heroes Act? https://www. cbpp.org/research/state-budget-and-tax/how-much-would-each-state-receivethrough-the-coronavirus-state-fiscal (2020).

28. Congressional Budget Office. Monthly budget review for July 2020. https://www. cbo.gov/system/files/2020-08/56497-CBO-MBR.pdf (2020)

29. Walczak, J. How the HEROES Act would allocate state and local aid for coronavirus relief. https://taxfoundation.org/heroes-act-state-local-aid/\#: :text=The \%2OHEROES\%20Act\%2C\%20introduced\%20Tuesday,installments\%20over\% 20the\%20next\%20year. (2020). 